\title{
Liderazgo de mujeres en el Valle del Cauca: cotidianidades y tensiones entre lo público y lo privado ${ }^{* *}$
}

\author{
Women leadership in the Valle del Cauca: daily life and \\ tensions between the public and the private spheres \\ Liderança de mulheres no Valle del Cauca: \\ cotidianidades e tensões entre público e privado
}

* Psicólogo de la Universidad del Valle y Magister en Filosofía de la misma Universidad. Profesor del Departamento de Estudios Psicológicos y miembro del Seminario de Estudios de Género de la Universidad Icesi. Correo electrónico: andres. castelar@correo.icesi.edu.co

\footnotetext{
** Este artículo es producto del proyecto de investigación "Trayectorias de vida de lideresas comunitarias: ámbitos públicos y privados”, octubre de 2013. El 8 de abril de 2015, el Seminario de Estudios de Género había planeado una sesión de trabajo para discutir este artículo con el profesor y sugerir algunas correcciones para su futura publicación. Lamentablemente, Andrés Felipe no pudo asistir a esta reunión: había muerto dos días antes. Ante este escenario el Seminario realizó las correcciones planeadas y, a modo de homenaje, las incorporó a este documento intentando respetar el estilo y las intenciones que animaron a su autor. Este proceso constituyó para el seminario un último trabajo colectivo con Andrés Felipe. Fue, al mismo tiempo, un encuentro y una despedida. Artículo recibido 12/04/2015 y aprobado el 25/04/2015.
} 


\section{Resumen}

Abstract

Resumo

Históricamente se han proyectado los conceptos de lo masculino y lo femenino como dicotomías compuestas de valores opuestos, siendo los valores que caracterizan lo masculino los que han sido socialmente privilegiados. Así, a las mujeres se les ha asignado roles como el reproductivo, en contraposición a lo productivo; el cariño, en contraposición a la fuerza; lo privado, en contraposición a lo público. No obstante, hoy se presentan casos paradigmáticos que desdibujan los límites de género aparentemente claros que imponían estas dicotomías. Este documento se deriva de un proyecto de investigación sobre la cotidianidad de mujeres lideresas comunitarias, quienes, por el trabajo que realizan y su vocación de liderazgo y poder, representan un ejemplo de lo difusos que pueden llegar a ser los límites entre los valores asignados a lo masculino y a lo femenino. En este artículo se busca identificar, en las vidas de estas mujeres, los conflictos y las facilidades con las que se encuentran al realizar un trabajo de liderazgo que las demanda subjetivamente y las obliga a poner en juego recursos para distinguir o hacer coherentes los ámbitos privados y públicos.

\section{PALABRAS CLAVE:}

Lideresas comunitarias | género | público | privado | vida cotidiana

Historically, the concepts of the masculine and feminine have been projected as composite dichotomies of opposing values, socially priviledging the values that characterize the male. Thus, women have been assigned roles as reproductive as opposed to productivity; affection, as opposed to the force; private as opposed to public. However, there are paradigmatic cases that are blurring the apparently clear boundaries of gender that imposed these dichotomies. This document is derived from a research project that explores the everyday life of women "community leaders" who, by their work and vocation of leadership and power, represent an example of how fuzzy the boundaries between the values assigned to the masculine and the feminine may become. This article seeks to identify, in the lives of these women, the conflicts and the facilities with which they have to perform a leadership work subjectively demanding and forces them to stake resources to distinguish or being consistent the private and the public.

PALABRAS CLAVE:

Community leaders | gender | public | private | everyday life 
Historicamente têm-se projetado os conceitos de masculino e feminino como dicotomias compostas de valores opostos, onde os valores que caracterizam o sexo masculino têm sido os socialmente privilegiados. Assim, às mulheres foram atribuídos papéis como o reprodutivo, em oposição ao produtivo; o carinho, em oposição à força; o privado em oposição ao público. No entanto, atualmente ocorrem casos paradigmáticos que borram as fronteiras de gênero aparentemente claros que impunham essas dicotomias. Este documento é derivado de um projeto de investigação destinado a explorar a vida diária de mulheres líderes comunitárias, que, por seu trabalho e vocação de liderança e poder, representam um exemplo de quão difusas podem ser as fronteiras entre os valores atribuídos ao masculino e ao feminino. O objetivo neste artigo é identificar, na vida dessas mulheres, os conflitos e as facilidades com as quais se encontram quando executam um trabalho de liderança subjetivamente exigente e que as obriga a comprometer recursos para distinguir ou fazer consistentes as esferas privada e pública.

\section{PALAVRAS-CHAVE:}

Líderes comunitárias | gênero | público | privado | vida cotidiana 


\section{Introducción}

Durante el año 2012, el Seminario de Estudios de Género diseñó y ejecutó un proyecto de investigación sobre el modo en que un grupo de mujeres caleñas, que reconocíamos como "lideresas comunitarias", conciliaba su vida privada con su acción pública. Para ello fueron entrevistadas 8 mujeres que lideraban en el momento "comunidades" muy diversas: desde grupos feministas hasta comunidades rurales, desde la causa estudiantil hasta la defensa de los derechos de los animales, desde el barrio hasta los avatares que enfrentan las mujeres transexuales. Así pues, el universo de mujeres estudiado era tan heterogéneo, como inconmensurable. En esta vía, este documento constituye un esfuerzo por reconocer elementos en común en las rutinas diarias y cotidianidades de estas mujeres; y caracterizar las tensiones y conflictos ocasionados por la incidencia social del género en sus vidas, en particular, la separación tradicional entre el mundo privado y el mundo público. Esta estrategia permitirá revisar algunos elementos que atraviesan las vidas de estas lideresas comunitarias y ponen en tensión, desde sus propias voces, sus identidades de género.

\section{Cotidianidades: cómo hacer algo extraordinario a partir de la rutina}

Matilde $^{1}$, lideresa feminista de 58 años, puede levantarse tarde, atender algunos compromisos, leer o escuchar música, sin la presión de "estar para alguien más”. El tiempo libre es todo su tiempo, y por ello no hace una división fría y calculada entre tiempo de trabajo y tiempo de no trabajo. Vive ella con plenitud las distintas actividades que se vayan presentando, sean recreativas o no, solitarias o en compañía. Debido a su condición de jubilada, no hay un día que ella considere de más trabajo, no hay presión por el tiempo -madrugar, atender horarios, recibir a otras personas, atender procesos exigentes-. El lunes es su día de menor actividad, lo que no quiere decir que no haga nada.

Con amigas de su edad ha conformado unos grupos que ella llama "combos" y que se coordinan a lo largo de la semana. "Tenemos como el combo de la piscina, el combo de ir a la viejoteca, en la semana nos ponemos de acuerdo para ver qué vamos haciendo. Pero también me gusta mucho estar sola y también hacer cosas yo sola. Soy muy independiente". Últimamente ha dedicado su tiempo al acompañamiento de mujeres en proceso de IVE (Interrupción Voluntaria del Embarazo²), ya que conoce los procedimientos legales que

1. Todos los nombres han sido modificados para proteger la identidad de las mujeres participantes de la investigación.

2. La Corte Constitucional colombiana declaró en 2006 que el aborto no es delito en los siguientes casos: "(i) Cuando la continuación del embarazo constituya peligro para la vida o la salud de la mujer, certificada por un médico; (ii) 
deben ser observados y que no pueden tener demora, así como las redes en las que se puede apoyar y las entidades que deben procesar los casos de mujeres que han sido víctimas de alguna forma de violencia. Explica:

Por ejemplo, si hay un acompañamiento [a mujeres víctimas de maltrato o abuso sexual] entonces toca ir a la EPS, si hay que hacer algo de la casa... a la Fiscalía... todo eso es de mucho estrésy de mucho tiempo para dedicarle, entonces a uno [el día] se le hace como pesado, y también da mucha rabia tantas barreras; y que no se cumpla con lo que está establecido. [Matilde, lideresa feminista, 58 años].

Podría decirse que es un asunto enrevesado, como todos los relacionados con la salud sexual de las mujeres, pero como el tema de la IVE está tan politizado, cuenta con particularidades y gestiones minúsculas que no se pueden pasar por alto. Esta politización va desde la negación directa de la atención hasta el proceso perverso de dar largas para que luego los procedimientos no se puedan realizar. También hay desgaste emocional ante las críticas, incluso de otras mujeres que trabajan en salud.

Matilde sostiene que en su caso no es fácil diferenciar lo privado de lo público, pues para ella esa distinción no permite reconocer la transparencia de las personas. Le resulta chocante ver que algunas personalidades proyectan ante la gente una imagen y son otro tipo de personas con sus cercanos. En cambio, su trabajo como mujer que ayuda a otras mujeres, no es algo que se pueda separar de su quehacer diario.

$\mathrm{Al}$ analizar la separación entre lo público y lo privado, Leandra, lideresa feminista de 32 años, va aún más allá en sus apreciaciones y comparte una afirmación categórica: la separación entre lo privado y lo público "no es algo estratégico, politicamente hablando,y además es una separación vil. Entonces es un compromiso político el no hacerlo". Tal como lo dice Matilde, hay una continua búsqueda de coherencia marcada por la necesidad de alejarse de prácticas patriarcales típicas, como llevar una doble vida, ocultando o simulando unas cosas y revelando otras.

Por el contrario, hay personas que rechazan esta suerte de "politización de sí", pues esperan que se reserven cosas para personas que pertenecen al círculo íntimo, entre ellas, las parejas. Usualmente, las parejas esperan que se limiten, que dediquen para ellos parte de su tiempo, de sus actividades, de su afecto, de su cuerpo. Sin embargo, las lideresas entrevistadas se resisten a hacerlo, al considerar que esa limitación es una traición consigo mismas. Una de ellas explica: “¡Uno se puede volver tan intimidante! Y

Cuando exista grave malformación del feto que haga inviable su vida, certificada por un médico; (iii) Cuando el embarazo sea el resultado de una conducta, debidamente denunciada, constitutiva de acceso carnal o acto sexual sin consentimiento, abusivo o de inseminación artificial o transferencia de óvulo fecundado no consentidas, o de incesto". En su calidad de enfermera, Matilde acompaña a mujeres durante el proceso de IVE y trabaja para que se garanticen sus derechos. 
mis prácticas se volvieron tan ofensivas (por lo intimidantes)... pero vos te acogés a eso cuando vas a interlocutar para cortarles la posibilidad [de que te menosprecien]".

En lo que respecta a la organización del tiempo, Leandra se esfuerza activamente por hacer que sus días no sean parecidos los unos a los otros. Al no tener que ofrecer un cuidado permanente a otros -es soltera, vive sola, no tiene hijos ni hijas- cuenta con el tiempo para ella misma y lo invierte de forma variable, sola o acompañada de sus amigas, quienes son sus "otras", a las que ama. Esto es algo a la vez muy provechoso pero complicado de manejar, pues la inestabilidad financiera en la que se mueve le genera muchas incertidumbres con las que debe estar dispuesta a vivir.

Para Fernanda, lideresa estudiantil de 23 años, la distinción entre tiempo libre y tiempo de trabajo es difícil de establecer, porque las actividades que realiza implican tanto actividades de logística-encuentro con grupos de base, gestión de procesos internos de la universidad-como continuos ejercicios de reflexión. Sus actividades se centran en la representación estudiantil, lo que supone escuchar al otro, conocer sus necesidades y apoyarlos.

Para Fernanda es clave mostrar coherencia entre decir algo y llevarlo a la práctica, entre ser capaz de ser auténtica y no crear una vida de mentiras, de poses. Esa coherencia es un reclamo incesante que hace a sus compañeros varones, a los que debe pedir respeto continuamente para que sean capaces de hacer en lo interpersonal eso mismo que hacen en el mundo público. Pero -al contrario de lo que sostienen Matilde y Leandra- diferenciar los espacios públicos y privados es fundamental en su cotidianidad. Lo explica así:

Yo, en un primer momento, era mucho más abierta, muy chistosa, muy confiada; le contaba todo a todo el mundo y no tenía problema con eso; no era de fijarme que si yo hago esto entonces van a decir tal cosa de mí, porque a mi me daba lo mismo, entonces no me importaba... si estaba con un man y terminábamos a los dos o tres meses y me metía con otro, para mí no había ningún problema. Ya después entro en un periodo como de desconfianza, de cerrarme totalmente, de decir que no se puede tener amigos porque se van a pegar las personas para caerle encima a uno, para destruirlo; $y$ bueno, una cosa como de resentimiento, más bien. Y por último ya uno aprende a mediar las cosas, a saber que uno no puede confiar en todo el mundo, y que tampoco es un requisito para uno vivir tranquilo, pues entonces que si pasó esto pues no, que mis amigos se están peleando por esta cuestión... [Fernanda, 23 años, lideresa estudiantil].

En todos los casos, las mujeres estudiadas hacen esfuerzos para mantener la coherencia entre lo que hacen y sus discursos. Por ejemplo, para Fernanda las alianzas, los acuerdos, las tácticas son claves en su quehacer, pues le permiten reconocer al otro, saber a quién le habla, de qué le habla, cómo lo hace. La palabra crucial para ella es "mediación”, algo así como alcanzar un punto intermedio que le permita sostenerse sin cambiar sus propios puntos de vista. Por ello, en algunos momentos su discurso será más audaz, más argumentado o más básico, dependiendo a quién se dirija. Sus encuentros con los otros 
van desde la vocería y el escuchar a los estudiantes de la universidad en todas las sedes, hasta actuar ante tomadores de decisión (ministros y líderes de despachos, miembros de la Mesa Ampliada Nacional Estudiantil (MANE), audiencias públicas en el Congreso de la República, etc.).

Tal y como ocurre con Fernanda, para Julieta -mujer afro de 40 años que lidera una organización que reclama derechos y atiende a población femenina infectada con VIHla rutina diaria está establecida y marcada por pautas rígidas, pues implica también el cuidado de sus hijas. Actualmente vive con su hija menor, mientras que la mayor vive en Argentina. Julieta desempeña, antes que nada, su rol de madre soltera. Sus días inician, entre semana, a las 4:30 a.m., para despachar a su hija al colegio. Esto implica no solo atenderla, sino también comunicarle su amor por medio de la comida: le prepara la aromática, le sirve el jugo, le pica la fruta. Después de eso, sigue siendo madre, pero esta vez de sus hermanas, compañeras de la organización que dirige. En la organización ella hace todo: desde el aseo del lugar hasta el pago de los servicios; desde imprimir las cuentas de cobro hasta buscar a otras personas para que le ayuden a resolver los problemas.

Actualmente sus compromisos con la organización son asumidos con mayor tranquilidad que antes. Ella dice estar aprendiendo a "soltarse", a despreocuparse por el "qué dirán" y a divertirse más. Gracias al apoyo de su psicóloga, ha aprendido a "sentarse a esperar" que la organización le devuelva cosas que ella le ha aportado. Nos dice: "Yo debía hacer de todo y responder por todo", lo que le implicaba asumir los gastos, las tareas y el trabajo. Ahora, gracias al paso del tiempo, a la edad, ha aprendido que necesita tiempo para ella misma y que debe hacer las cosas con calma.

Julieta destaca su rol de madre, y seguir aprendiendo día a día cómo ser mejor mamá. Evitar el regaño y la sanción, ser más comprensiva, más "compinche". Se esfuerza por comunicarse de forma continua y directa con sus hijas, escribirles mucho, decirles lo que siente por ellas. Sin embargo, Julieta aclara que cuando hay proyectos en desarrollo entonces tiene tareas distintas todos los días. Ella es clara al hacer la separación con su rol de madre. Pero así mismo, en lo económico, el llamado rebusque le ocupa igualmente todo el tiempo, pues no tiene una situación económica definida.

Algo parecido le ocurre a Paloma, lideresa transexual, para quien la jornada de trabajo se duplica. En el día se dedica a los oficios domésticos, y en la noche realiza visitas a sitios frecuentados por mujeres trans que ejercen el trabajo sexual. Para estas últimas imparte talleres sobre el cuidado de sí y Enfermedades de Transmisión Sexual (ETS). Además, Paloma opera como "la recepcionista" de la Fundación en la que trabaja, distribuye preservativos, recolecta información, lo que implica tomar nota de los casos denunciados, hace el acompañamiento a los puntos donde se tiene que hacer el proceso jurídico y otras actividades.

Así, es posible reconocer en su día a día un ejercicio de cuidado de las otras, ya sea con labores reproductivas en el día (oficios de casa, atención secretarial en la fundación), 
o con labores de educación, acompañamiento y apoyo en la noche. Lo anterior implica extenderse a aquellas acciones del Estado que no son atendidas, con el fin de solucionar (o al menos, participar en la solución) de los problemas que las aquejan, y también atraer la atención de la ciudadanía sobre los problemas de esta comunidad que ha sido especialmente aquejada por prácticas de violencia y exclusión.

En el trabajo de campo de Paloma se puede reconocer el tipo de comunidad a la que se llega: mujeres trans que se ven forzadas a ejercer el trabajo sexual en zonas urbanas de Cali, en horas de la noche y la madrugada. En esta actividad, que ella llama "labor de campo", tiene que conocer casos críticos y recoger información de los casos de violencia y asesinato que afectan a esta población.

Para Carolina, estudiante universitaria y lideresa animalista de 25 años, la rutina diaria se reparte entre su vida universitaria y el apoyo a la Fundación animalista que dirige. Afirma que su relación es más afectiva con los animales que con las personas. El compromiso con los animales es notorio y lleno de detalles inimaginables para la mayoría. Su rutina diaria se hace sobre la marcha, atravesada por el trabajo, la militancia, la academia. Al describir su día más ocupado, asegura "acomodar" el trabajo de la Fundación animalista que dirige en función de sus necesidades y no al contrario. Los ciclos de ocupación semestrales están en función de las actividades de la universidad, atravesados ocasionalmente por fechas cruciales para las actividades de militancia (por ejemplo en diciembre, cuando es necesario informar y discutir con las personas sobre el maltrato animal de las corridas de toros, del uso de la pólvora, etc.). Entonces, el trabajo militante permite reconocer ese ambiente patriarcal que le acusa de ser "demasiado feminista" porque defiende la fuerza "física" femenina; en una clara distorsión -muy masculinizada-de la idea del feminismo.

En su caso, otra estrategia para gestionar su ocio es el baile “...que es la única manera en que yo puedo sentirme plena, ciento por ciento feliz". El descubrimiento del baile y la rumba ha sido de gran provecho para ella y su pareja, pues el baile es visto por ella no solamente como una actividad sino como un ritual que la hace sentir plena y feliz. El hip-hop y la salsa son para ella los ritmos que más disfruta, porque el baile la conecta con la espontaneidad y con la feminidad.

Por otro lado, la rutina de la semana de Ernestina, lideresa campesina de 48 años, quien se mueve en el sector rural, se centra en el apoyo a su comunidad y la atención a su familia. Relata que los días más pesados son los fines de semana, cuando las comunidades se pueden reunir. Un lunes o martes será más suave debido a que no hay tantas actividades, y por ello los puede dedicar a realizar visitas a grupos de mujeres o talleres pedagógicos con estudiantes. Los días de descanso de los demás campesinos son sus días de mayor actividad, para poder facilitar los procesos. Los viernes, cuando hay mercado campesino, se desplaza para adquirir productos. Su trabajo de liderazgo es muy amplio y variado, aunque se podría decir que gira en torno de dos ejes: el educativo y el proac- 
tivo. La capacitación a las personas es vital para permanecer alerta ante los cambios, las políticas y las luchas por defender su sector; mientras que la proactividad, que va de la mano con el objetivo anterior, busca gestionar acciones concretas y procesos de tipo jurídico, logístico, táctico.

Ernestina, en un día normal, madruga a las 5:30 am, se baña, cuela el café y “despacha a su hija”. Después saca a la mascota familiar a pasear. Viene luego el desayuno, y empieza las actividades de sostenimiento de la casa. No cocina, pues la comida se prepara en el restaurante de su compañero. Su tiempo personal suele ser flexible, pues depende de otras personas que la puedan buscar. Sea que la llamen o que la busquen, nunca dice que no a las necesidades de los otros. Disfruta ver programas de televisión que aborden temas relacionados con la naturaleza y lo hace cuando puede descansar; los lunes en la noche, por ejemplo. Confiesa tener muy poco tiempo para dedicar al cuidado de sí misma, para arreglarse el cabello o las uñas, debido a que no tiene tiempo y a que su trabajo le exige condiciones en las que ese cuidado no le dura. Curiosamente, sus descansos semanales terminan los viernes, pues el sábado y domingo empieza el "corre corre".

Una situación similar vive Fabiola, lideresa de un barrio marginado del oriente de Cali. Ella suma a su trabajo como lideresa barrial, la administración de los gastos del hogar y la realización del trabajo doméstico. En su trabajo debe estar pendiente de sostener los tejidos y las redes de confianza y participar también en los trabajos colectivos. Eso le implica organizar el tiempo, separado entre la mañana y la tarde en función de una agenda diaria, distribuir las actividades, etc.

Hay un elemento en común en el trabajo de algunas lideresas: los meses de más trabajo coinciden con fechas conmemorativas de las actividades en las que se destacan. Por ejemplo, para Matilde, las fechas de más trabajo son las conmemorativas del feminismo. De igual manera, para Julieta es crucial concentrarse en las fechas de conmemoración o reconocimiento internacional relativas a las mujeres: los meses de marzo (Día Internacional de la Mujer) y noviembre (Día de la No Violencia contra la Mujer), además del $1^{\mathrm{O}}$ de diciembre, por la conmemoración del Día Internacional de lucha contra el VIH. Por su parte, Fernanda considera que su ajetreo coincide con los procesos de representación estudiantil; y Ernestina, con los propios en el tema rural; mientras que el trabajo de Carolina se incrementa en épocas como fin de año y octubre, para la celebración del Día de los Animales.

Así, los ritmos y las rutinas de las participantes figuran entremezclados y no establecen de manera sistemática los límites usuales entre lo privado y lo público, salvo en el caso de Fernanda, que está estableciendo estos ritmos pero en aras de su salud y bienestar personal, y de Julieta, que ya lo hizo por las mismas razones. El lugar dado al otro es muy importante, no tanto porque consideren que esa sea su naturaleza, sino porque se sienten parte de un entramado social en el que pueden participar y desenvolverse con comodidad. 


\section{Objetos y espacios: tácticas para defender la independencia}

Siguiendo la propuesta de Michel De Certeau³, esta investigación quiso reconocer el lugar del "hacer" en la vida cotidiana, de cara a dar lugar a la interacción (con las herramientas, con las personas) antes que suponer que el liderazgo es un fenómeno mágico, espontáneo o limitado a unos pocos. Así, en este apartado es importante reconocer el lugar del "hacer", en la medida en que hay un conocimiento sobre cómo llevar a cabo procesos, cómo solucionar problemas y cómo atender necesidades.

Las rutinas y las cotidianidades son entonces tácticas para hacer algo al tiempo que se lucha contra los fuertes. En una estabilidad social en continua crisis que siempre anuncia el riesgo del desmoronamiento, las tácticas se articulan con una nueva forma de ganar sin explotar al otro. En este contexto es importante darle un lugar a los momentos, a los espacios y a los objetos, pues es en la interacción con ellos transcurre la vida cotidiana. No necesariamente serán los instrumentos canónicos, sino sobre todo los útiles, pero también los más apreciados, los más necesarios. Para Matilde, por ejemplo, su instrumento de trabajo es la palabra. A través del encuentro con la otra, siente que puede ayudar a las mujeres a mirarse hacia adentro, a enfrentar los límites impuestos por el patriarcado. Como no le gusta el reconocimiento mediático, cree que en ese sentido ese conjunto de rasgos de lo femenino son sus instrumentos de trabajo, que le permiten mirarse "hacia adentro" y enseñar a las demás a hacerlo.

A Matilde no le gusta establecer un ritmo de trabajo constante ni mucho menos un listado de actividades que desarrolle de forma rutinaria. Un día típico en su vida se caracteriza por ser pausado, sin presiones externas. Para ella, su comunidad son las mujeres, sus hermanas: estudiantes universitarias, mujeres en proceso de IVE, mujeres con cáncer, así como las jóvenes que la buscan para incursionar en la causa de los derechos sexuales y los derechos reproductivos. "Yo pienso sobre todo en las amigas. Ellas son como mi claridad; la defensa de los derechos sexuales y reproductivos, el cuidado del cuerpo y de la salud, ese es mi fuerte".

Matilde rechaza el uso afectivo de los objetos, porque considera que están destinados a crear dependencias y terminan cosificando al ser humano. Cada vez necesita menos herramientas y menos cosas: en su jubilación se ha dado a la tarea de desprenderse y aprender a vivir con lo justo y lo necesario. No obstante, hay una práctica importante en su vida y es su gusto por la cocina: ella sabe y reconoce que es una labor que ha esclavi-

3. Para de Certeau: “[Hay] prácticas [que] ponen en juego una ratio "popular”: se formulan esencialmente en "artes de hacer" esto o aquello, es decir: en consumos combinatorios y utilitarios. Estas prácticas ponen en juego una ratio popular, una manera de pensar investida de una manera de actuar, un arte de combinar indisociable de un arte de utilizar" (2OOO: XLV). 
zado a la mujer por generaciones; por eso se está dando a la tarea de incursionar en su aprendizaje, pero esta vez por placer.

Al igual que para Matilde, la cocina es el eje central en la vida de Julieta, lideresa afro de una organización para mujeres con VIH. En su tiempo libre se dedica a ello, y ha desarrollado grandes habilidades culinarias, al punto que hoy es su principal medio de ingresos, pues constituyó una empresa de comida del pacífico. Julieta se acerca a las personas por medio de la comida, es decir, asistiendo a quienes no la tengan. Ella siente que a través de su sazón, por llamarlo de alguna manera, entra en contacto con los otros.

Por su parte, Fabiola describe su entorno doméstico como el espacio clave de su vida. Sin embargo no lo describe como algo con lo que tenga muchos apegos, debido a los gastos en los que tiene que incurrir: pago del lote, pago de servicios públicos. Los objetos son, para ella, también una carga. También es necesario recordar las representaciones negativas sobre el barrio que lidera y cómo estas afectan su relación con los objetos. Al respecto, ella relata una situación que se le presentó cuando estaban haciendo el tránsito de la invasión al barrio:

Cuando estábamos terminando el proceso de invasióny y a el sector estaba seguro, había una vecina que tenía un hijo guerrillero. Cuando yo empecé a invadir, nos tocaba trasnochar, entonces yo me ponía botas pantaneras, andaba con machete, me ponía una chaqueta grande y mirando a la gente a ver qué hacía. En el asentamiento a mí todo el mundo me decía "la guerrillera". Cuando ya montamos y todo, a la señora no le salían los subsidios. Cuando un nieto de la señora me vino a buscar, diciendo que el hijo de la señora me andaba buscando porque a ella no le salía el subsidio y que le dijeran quién era "la guerrillera" porque él necesitaba hablar conmigo. Entonces el nieto de la señora vino a decirme que no fuera a saliry que me escondiera porque ese muchacho estaba ahíy de pronto me hacía algo porque él pensó que yo le estaba frenando el subsidio. A partir de ese momento nadie me volvió a decir "la guerrillera" [...] de ahí los ánimos se calmarony de ahi si traté de hacer todo lo posible porque a esa señora le llegara el subsidio. [Fabiola, lideresa barrial].

Ernestina, lideresa campesina, recurre a los dispositivos tradicionales y a los tecnológicos, por igual, para conectarse con las tareas de su comunidad. Usa el computador para leer correos, tareas, planes de trabajo, actividades pendientes. Esto le sirve para mantenerse al día con cronogramas y proyectos pendientes; lo mismo que su cuaderno de apuntes, que le sirve de agenda.

Leandra, feminista de 32 años, considera la relación con sus compañeras de vida como fundamental y necesaria para desempeñar su trabajo militante. Las describe como sus hermanas y habla de ese amor de forma plena, desenfadada, sin eludir el tema de lo lésbico. Tomar partido por la pareja en detrimento de la amiga le resulta amargo, debido a que se nos enseña que si se "ama" a la pareja" entonces hay que cambiar las cosas porque a la amiga no se la puede amar. Leandra describe su relación con las amigas como "sanadora", pues se permiten llorar, soñar, pensar cosas juntas. 
Los objetos para Leandra son esenciales en su rutina: recurre a dos materiales: su agenda y su cuarto; y a un objeto virtual: su perfil de Facebook. El cuarto de Leandra y los objetos que hay en él -sus pertenencias, los regalos que le han hecho, los peluches que han llegado, elementos con los que ha conformado su altar personal- reflejan su personalidad y hacen parte de su historia. Estos objetos han llegado a ella por solidaridad y no porque los haya comprado: han sido regalados o donados. Así ocurre con su indumentaria, pues no la compra sino que la trueca, o se la obsequian las personas que la quieren. En sí, la ropa es un elemento importante para ella, porque hay un ejercicio de travestismo con la indumentaria. Al comienzo le preocupaba lucir bien ante los demás; sin embargo, cuando se percató de que esa práctica iba en contra de su forma de verse en el mundo, empezó a transformarla. Si una prenda de ropa llega a ella y la hace sentir bien, la usa, de lo contrario, no está interesada en arreglarse o incluso incomodarse para otros.

También da enorme importancia a su perfil de Facebook, pues desde él hace lo que llama un "activismo virtual". El perfil se ha vuelto importante en el último año. Este nuevo espacio virtual le ha proporcionado un nuevo tipo de aprendizaje del activismo en temas de diversidad sexual y de género, y le refuerza la idea de que esa participación es una práctica política que pasa a través del cuerpo.

En la misma clave de lo virtual, Carolina, lideresa animalista, considera el computador como uno de los objetos claves de su trabajo, así como los planes de celular que le permiten contactarse con sus aliados animalistas. De igual forma, la Internet es hoy su fuente directa de información, pues la búsqueda en portales informativos como Youtube es fundamental para recopilar datos en tiempo real y sensibilizar a sus redes. En ausencia de un espacio físico de trabajo, la organización que dirige es operada a distancia, y en cualquier tiempo robado al trabajo o al estudio. Carolina trabaja durante las clases: chatea o transcribe actas mientras atiende las sesiones. Cuando se reúne en un lugar público, la camiseta que porta le sirve también para atraer nueva gente. Su labor también la ha llevado a producir objetos, lo que le permite valorar de modo diferente su relación con las cosas. Ha hecho trabajo desde lo expresivo -obras de teatro, por ejemplo- hasta de comunicaciones, elaborando el boletín informativo que envía a las agencias de prensa.

Los objetos empleados aquí se caracterizan por facilitar el contacto con el otro: la palabra, el celular, el perfil de la red social virtual, el chat, son todos objetos y herramientas que apoyan y fortalecen los vínculos, además de que permiten crear otros nuevos.

\section{Vida económica y vida ordinaria}

En la división tradicional entre lo privado y lo público, acostumbramos a pensar el trabajo como un elemento aislado de la vida personal. Sin embargo, las relaciones con la producción están encontrando desafíos y rupturas muy interesantes, en función de los 
cambios actuales en la vida laboral, en las formas de articulación a lo social y en los ritmos que separan los tiempos de ocio y producción. En clave de la propuesta de Lazzarato y Negri, por ejemplo, es necesario acercarse a:

(...) la transformación radical del sujeto en la relación con la producción. Esa relación ya no es una relación de simple subordinación al capital. Por contra, esta relación se plantea en términos de independencia del tiempo de trabajo impuesto por el capital. En segundo lugar, esta relación se plantea en términos de autonomía de la explotación, es decir, como capacidad productiva individual y colectiva, manifestándose como capacidad de goce. La categoría clásica de trabajo se muestra absolutamente insuficiente para dar cuenta de la actividad de la fuerza de trabajo inmaterial. (Lazzarato y Negri, 2002: 4).

En esta vía, más que por "cómo se ganan la vida" estas mujeres, nos preguntaremos por las estrategias que emplean para gestionar la subsistencia. Ello no pasa solamente por el dinero, sino también por medidas como el intercambio, el pacto, así como el recurso de los vínculos afectivos. Finalmente, es posible reconocer algunas prácticas de resistencia que se hacen presentes en la cotidianidad de estas mujeres.

Para darle connotación al concepto de "resistencia", se adoptará la propuesta de Mary Holmes, para quien esta se define en las "luchas contra la injusticia por tener el control de sí sobre las propias acciones y de la vida" (2007: 81, traducción del autor). Estas ideas son necesarias para comprender la tensión entre la dedicación a los demás y la vivencia individual. "La mayoría de las mujeres aún dedican buena parte de sus vidas a cuidar a otros. El modo como ellas lo hacen, es algo que ha cambiado gracias a la economía global de hoy" (Holmes, 2007: 82). De modo que no es posible sostener que la independencia de las mujeres de hoy pase exclusivamente por su articulación al mercado laboral y/o la masculinización de sus relaciones.

Matilde, feminista de 60 años, por ejemplo, expresa las razones de su alejamiento de lo académico: lo ve como un sistema muy patriarcal, demasiado impositivo, que no reconoce las diferencias. Por eso, para ella es necesario hacer una reivindicación de la singularidad. En su caso, la llegada del médico Julio César Payán trajo un nuevo paradigma centrado en la terapia holística, lo que la llevó a concluir su ruptura con el esquema médico tradicional. Sus críticas al esquema médico evidencian también un descontento con los sistemas políticos típicos.

De nuevo aparece un significante importante en su vida: sus amigas, a quien llama sus hermanas. $Y$ es que Matilde reconoce su profunda solidaridad con las demás mujeres. Declara que se encuentra en la esfera del trabajo no productivo, mas no lo asume como una forma despectiva de articularse a lo social. Por el contrario, disfruta de la vida cotidiana, de la vida íntima, y goza de libertades y privilegios como el de la jubilación. Sin embargo, sigue con otras actividades que le representan ingresos adicionales, como la venta de algunas producciones culturales -agendas feministas, revistas- $\mathrm{y}$ también 
apoya el sector de la salud y, en particular, a las mujeres con cáncer de mama, con las que ha aprendido mucho.

Pero si Matilde goza de los ahorros de toda una vida de trabajo articulado socialmente, Leandra, feminista de 32 años, en cambio, rechaza abiertamente la indignidad de la empleabilidad tradicional y las formas de inserción en la rutina productiva propia del sistema. No aprendió a vivir con un trabajo fijo, asalariado; en cambio, le interesan otras prácticas de inserción económica. Su vida laboral se ha centrado cada vez más en proyectos de participación, que en ocasiones equivaldrían a contratos de prestación de servicios, lo que implica vínculos contractuales distintos, más flexibles, en vez de rutinas laborales que obligan a rendir cuentas a desconocidos, tener que "proyectar una imagen adecuada para los clientes" o adecuarse a horarios estrechos.

Leandra describe toda una serie de tácticas para encontrar empleo y conservarlo. El trabajo cotidiano es un permanente tire y afloje, en el momento de la entrevista tenía dos: uno en una academia de inglés y otro con una fundación feminista. Su vida económica es fluctuante; gestiona recursos para sostenerse, fundamentalmente en sus redes de apoyo, entre las que se cuentan la solvencia de la hermana y la ayuda de sus amigas. Hay un sinnúmero de tácticas de supervivencia que ella interpreta como apuestas políticas para no ser esclava del dinero.

En el escenario laboral, la Fundación en la que labora es un espacio que asume no tanto para cumplir tareas y obligaciones, sino para hacer conexiones, establecer redes y alcanzar coherencia en su discurso. Por ejemplo, en su manejo de horarios laborales, acude cuando se le necesita, y no porque deba estar allá. Siente que su trabajo en la fundación es cercano al activismo comunitario, por eso no se siente agotada ni explotada y ha superado la tensión de "reventar el dinero". En este sentido, Leandra es enfática en afirmar que no concibe la idea de tener que trabajar en algo que no le guste.

Algo parecido le ocurre a Julieta: en este momento está entregada a aquellas cosas que la apasionan. Como se mencionó antes, Julieta se acerca a las personas por medio de la comida, es decir, asistiendo a aquellas personas que no la tienen o comunicando su afecto a través de su sazón. El acto de servir la comida es casi un ritual, una ceremonia en la que está dando amor, lo hace porque sus amigos o sus hijas se lo merecen. Intenta mantenerse ocupada, el exceso de tiempo libre la deprime; así como odia el virus con el que vive y los efectos del medicamento. Para pasar el tiempo libre se divierte en el campo, sale de la casa al cine, a escuchar cuenteros y a otras actividades; siempre en compañía.

Su carrera laboral empezó como encargada del aseo en una corporación social muy relevante en la ciudad de Cali, lo que la llevó a involucrarse en lo político y a relacionarse con activistas de izquierda. Julieta ha puesto en juego diversas estrategias de supervivencia y de gestión de lo económico y lo financiero. Esos procesos pasan sobre todo por la solidaridad. Es el caso de un grupo de ahorro al que pertenece y con quienes tiene una relación muy estrecha. Al respecto Julieta comenta: 
Una de las mayores satisfacciones que me ha dado la vida es un grupo que se llama "compinchería", grupo de mujeres ahorradoras, es un fondo de ahorro que tenemos. Yo soy una de las menores y la única que no es profesional, pero el fondo de ahorro es un pretexto, porque lo que nos convoca es otras cosas, como hablar, porque no tenemos coordinado de quése va a hablar pero eso va fluyendo. Que la una es empresaria, asi no haya hecho sino quinto de primaria, pero maneja su empresa; la otra que es más espiritual, pero no nos mete sus cosas, sino que habla y siempre nos queda algo... Sabemos que en ese fondo nos estamos prestando nosotras mismas pero ese fondo sigue fluyendo... es algo muy bonito. [Julieta, lideresa afro, 41 años]

Si bien su espíritu comunitario se mantiene, en este momento está replanteando su vida; gracias a una amiga terapeuta está redefiniendo su prioridades, concentrándose en su empresa y su vida íntima. Julieta sostiene que el liderazgo ha aportado muchas cosas positivas a su vida personal y también en el plano de las relaciones con las instituciones. Su idea de ciudad ha venido cambiando de la mano de las distintas acciones que hace como lideresa.

Ese mismo aprendizaje lo reconoce Paloma, quien participa en una Fundación de ayuda a mujeres trans, lo que le representa un ingreso variable. Pero cuando no hay trabajo en la Fundación, es necesario recurrir nuevamente al rebusque en los oficios asignados para las mujeres trans.

Ernestina, lideresa campesina, ha manejado de modo variable su situación económica. En el momento de la entrevista no contaba con ingresos fijos propios. Anteriormente los había tenido en actividades diferentes a su liderazgo, como un negocio de comidas rápidas que su compañero tenía antes de ser forzados a desplazarse del lugar de origen. Ahora recurre a otros ingresos variables, como la venta de productos por catálogo y la venta de artículos a sus compañeras. Las ofertas laborales son bien escasas y más para las mujeres, pues casi todas son para hombres. Ha tenido que aceptar "trabajos de formularios y visitas domiciliarias" por la necesidad de engancharse laboralmente. El trabajo en ventas a veces dificulta el trabajo comunitario, porque las organizaciones campesinas tienen recursos muy escasos que no siempre alcanzan a cubrir todas las necesidades, y es necesario recurrir al apoyo internacional para realizar los proyectos fijados, de lo contrario no se lograrían cumplir.

Fernanda, además de su papel como representante estudiantil y de su condición de estudiante, trabaja como maestra en un colegio materno infantil, enseñando el idioma inglés a niños de tres a cinco años. Cuenta con el apoyo de su familia, y no lo hace por necesidad financiera, pero el trabajo le da independencia económica de su padre, y de paso es un aprendizaje sobre su propia vida. Este trabajo se articula con la universidad, pues tiene que ver con su proyecto de grado.

Carolina ha producido camisetas representativas que han servido para el sostenimiento de la fundación que dirige; además de ser activista es monitora académica en la 
Universidad, y también trabaja como mesera. Aporta \$5.0oo mensuales a la fundación, su trabajo es gratuito y voluntario.

Dentro de las prácticas de sostenimiento e inserción en el trabajo, encontramos toda una variedad de tácticas de inserción laboral, de gestión del dineroy, sobre todo, de apoyo mutuo que pueden pensarse como rebusques. Desde el ritmo sosegado y disciplinado que da la jubilación de Matilde, pasando por el trabajo estable de Fernanda, hasta la incertidumbre de la economía de Julieta, Ernestina y Fabiola, es posible reconocer un esfuerzo (en mayor o menor medida) por no hacer del dinero un dios, para no depender de él. El dinero es un medio, no un fin en sí mismo. De ello da cuenta la posición ética de Leandra, quien se esfuerza por no usarlo y no tener que recurrir a él.

Son muy interesantes los recursos a los que acuden estas mujeres, en tanto evidencian su ingenio para ir más allá de la relación persona-dinero y fortalecer, en cambio, la relación con los cercanos. Quizás la más destacada es la cocina, lugar socialmente asignado a la mujer y leído como un lugar de reproducción de los oficios; si bien desde la visión masculina es un espacio menospreciado, es posible recurrir a estrategias discursivas que le cambien el sentido cotidiano. Por ejemplo, como lo hacen Julieta o Matilde, y en menor medida Fabiola, para comunicar afectos a los demás. Cocinar se vuelve un gesto de amor, una atención al otro, una forma de dar afecto.

\section{Lógicas de acción: tensiones con las instituciones y nuevas modalidades de integración}

Para referirse a las lógicas de acción que estas mujeres ponen en juego en su vida cotidiana, en especial las lógicas de integración (de formación de grupos) y las lógicas estratégicas (de competencia), es necesario reconocer el lugar primordial que ocupa el lenguaje en la construcción de la realidad personal. Más que una herramienta que usan las personas para explicar lo que les ocurre, creemos importante entender el lenguaje como un mediador simbólico que otorga sentido a las situaciones y procesos que se presentan en la vida cotidiana. Las palabras cargan de significado a las situaciones que se presentan en el día a día (Arias, González y Fernández, 2009: 640).

No es necesario esperar a la conformación de condiciones objetivas para que las dinámicas sociales se transformen; el lenguaje también es un generador de cambios a través de las estructuras discursivas que fomentan la opresión y la inequidad. De este modo, mediante las palabras es posible subvertir un entorno viciado de condiciones de desigualdad o de limitaciones u obstáculos para alcanzar los propósitos personales o de la comunidad (Lazzarato y Negri, 2002: 9).

Se analizarán las lógicas de acción empleadas por las participantes en la investigación para manejar la distinción entre lo público y lo privado. Cómo se las arreglan para lidiar 
con su vida personal y al tiempo con su vida como lideresas, como agentes de cambio abiertas al mundo de lo público; cómo se apropian (o, por el contrario, rechazan) esta distinción; y cómo hacen para lidiar con ella frente a sus seres queridos, sus pares, los agentes del Estado, etc. Estas dificultades y tensiones no son las mismas para todas, pero son claves a la hora de comprender el lugar que dan a la significación de su lugar mediante el lenguaje. Se destacarán las metáforas empleadas para referirse a situaciones o procesos, y para entender los modos de entenderse con otros.

En el caso de Matilde, feminista de 60 años, sobre sus relaciones afectivas tiene la claridad de no "vivir con alguien", pero sí "estar con alguien": esto significa tener amigas, crear y nutrir relaciones. Para ella es muy importante permanecer coherente con lo que dice, en ese sentido, juzga clave mostrar que es posible llevar su vida felizmente sin una pareja. Por eso tiene muy pocos amigos varones y, en cambio, prefiere a las amigas mujeres. "Los hombres vienen buscando dominary establecer control. Mejor estar con amigas porque son cómplices y no juzgan". Sostener estas amistades y crear nuevas es su forma de integrarse a las redes de apoyo a las mujeres en la región: lo táctico poco a poco se convierte en estratégico.

Para Matilde, si bien hay unas peleas que ya no vale la pena dar porque no son pertinentes, considera necesario seguir siendo clara consigo misma. Por ello prefiere centrarse en un solo tema, en una sola lucha: la salud sexual y la salud reproductiva de mujeres en condición de vulnerabilidad, como las mujeres con las que trabaja. Con estos vínculos, que van y vienen entre lo público y lo privado, ha logrado participar en la conformación de redes, establecer conexiones, dar y recibir apoyo, liderar procesos de cambio y continuar en su rol de multiplicadora y de figura clave en el acompañamiento en salud sexual y reproductiva.

Matilde siempre ha demostrado dos elementos que la diferencian ante los demás: la radicalidad y el compromiso pleno con su trabajo. Sin embargo, con el paso de los años, se ha notado una modulación de esa visión tan fuerte y dura que perciben los otros. Esa modulación es el reencuentro con lo femenino que ella rechazó en su madre: el sometimiento, la sumisión, la cocina, entre otros.

Julieta, lideresa afro y defensora de mujeres infectadas con VIH, en cambio, se ha visto enfrentada a otras barreras, relacionadas con su origen étnico, con el hecho de no tener un título profesional que le abra las puertas a la estabilidad laboral. Estas limitantes estuvieron presentes en la constitución de la organización que lidera y dificultaron la gestión para el espacio físico y los recursos para la misma. Julieta señala que si bien se asume como feminista, ha chocado con otros sectores feministas, especialmente de la academia. Siente, en ocasiones, que su proceso ha sido utilizado por ciertas agrupaciones que buscan sacar provecho personal y no se preocupan en sí por las necesidades de las mujeres. No obstante, su trabajo le ha permitido ampliar vínculos con organizaciones estatales y del tercer sector; y sin duda ha cosechado logros que ella prefiere celebrar en 
silencio: "no hay que ser como la gallina que pone un huevo y hace much a bulla, sino como los peces que ponen muchos huevosy nadie se da cuenta de la incidencia que están haciendo". De fondo, Julieta reconoce que, sin proponérselo, se ha convertido en modelo a seguir para otras mujeres que también lideran sus procesos. Mujeres que ha conocido a través de las distintas asociaciones y redes, mujeres que viven con VIH y que la conocen a ella, ven su empuje y quieren seguir viviendo, tomarse los medicamentos, emprender procesos. Las redes de mujeres les han permitido superar las barreras y los obstáculos.

Las dificultades no solamente se presentan con las instituciones o los grupos con los que dialogan. Carolina, lideresa animalista, por ejemplo, habla de las formas mediante las cuales se asume la "feminidad" en un contexto de trabajo tan masculino como la acción militante. Carolina emplea estratégicamente una imagen de mujer que permite lidiar mejor con las instituciones. Para muchos puede resultar novedoso ver a una mujer liderando una marcha, en particular en Cali. En ocasiones ello no es tan beneficioso, porque por ser mujer puede que no la tomen en serio.

Se describe a sí misma como de carácter fuerte. Ella ha buscado ser independiente de los varones, al menos en el tema de la fuerza física, tratando de no depender de alguien. Como ocurre con Matilde, atribuye esos malos entendidos a la fuerza de su carácter. Asegura, sin embargo, que compensa esta fuerza con su performance de baile. En esos entornos sí usa una indumentaria muy femenina, pues está por fuera de su trabajo o de su estudio. Ahora bien, es consciente de que no todo el mundo entiende que su causa animalista es una lucha política, pero también ética. Más que liderar a personas, Carolina considera que lidera una causa por los animales. Por eso recalca que más que ambientalista, es animalista. Y señala cómo la lucha ha migrado de la manifestación a la discusión política racional, en el contexto de trasformación de los marcos legales. En ese sentido la manifestación es importante porque permite impactar mediáticamente. No importa tanto la presencia de un gran público presente, pues ahora no es la aglomeración de la masa sino más bien el impacto expresivo a través de medios. Este impacto les ha permitido hacerse a un lugar político en la ciudad y los ha llevado a iniciar la búsqueda de alianzas con concejales y con la administración pública.

Esta "lucha" difiere de la que ella define como "adolescente" o protesta gratuita. Dice que su proceso no es "Todo corazón”, como le ocurre a muchos activistas. Ella reconoce la necesidad de entrar al juego político, que percibe fundamental y no desligado de su parte académica. Admira a mujeres que lideran procesos pero que también investigan, producen saberes sobre sus proyectos animalistas, se convencen de sus argumentos y los defienden.

Fernanda, lideresa estudiantil, también refiere lo complejo que ha sido tener que priorizar el tema de la representación estudiantil, que le exige tiempo completo, frente a sus procesos personales. Sin embargo, esto también le ha exigido crear una disciplina, manejar relaciones con directivas, ser capaz de reconocerlos a pesar de las diferencias. 
También está el asunto de tener la disciplina previa de estudiar un tema, de argumentar las ideas, estudiar las resoluciones, los pronunciamientos, las decisiones que están en juego. Además afrontó la tarea de conocer las necesidades de los actores propios de la universidad, para poder escuchar y atender a esos actores internos en función de cómo operan. Resulta interesante notar que Fernanda es la que más señala la presión que ejercen sobre ella los grupos que le reclaman informes y cuentas sobre su actividad. En sus palabras: tiene que estar "comunicando sobre la marcha todo lo que va a pasar, para que la gente no espere que el Todopoderoso vaya a hacer algo, porque uno no es el Todopoderoso. Uno también estudia, trabaja, come, siente. Y a veces la gente cree que no, que uno está sólo para eso. Entonces lo ven a uno como el personaje principal, como el que tiene que hacerlo todo". La clave ha sido la capacidad de interlocución interestamentaria, la mediación y la necesidad de apelar a la flexibilidad y a la concertación.

Las pequeñas luchas de Fernanda muestran cómo la "feminización" del trabajo de liderazgo masculino pasa por la reivindicación de su identidad personal. Mientras para los hombres las cuestiones sentimentales, como la relación de pareja que no funciona, son interpretadas como "bobadas" a las que "no hay que pararle bolas", ella defiende su derecho a sentir, a expresar sus emociones por medio del llanto; lo que implica enfrentarse consigo misma continuamente, pues al mismo tiempo se siente débil.

Por su parte, Paloma, lideresa transexual, recuerda con respecto a sus estrategias de supervivencia que el trabajo sexual no fue una opción a la que llegó de forma voluntaria, sino que se vio presionada por la falta de ofertas laborales. Por esa razón, la inserción en el mundo del activismo y la colaboración con otras mujeres trans le ha permitido salir adelante. En su caso, los vínculos establecidos con las organizaciones que luchan por los derechos de las mujeres le han permitido sentir el liderazgo en clave de cambios en su vida personal, y también en función de las representaciones sobre su ser.

En ese sentido, lo que Paloma entiende por liderazgo es "servir como una forma de devolver una gratificación". Sus aportes como lideresa los ve como un logro colectivo, no individual. Gracias al trabajo en la fundación, Paloma asegura haber ganado seguridad, hablar mejor entre mujeres trans, e igualmente a mejorar su discurso frente a otros públicos.

Desde otra perspectiva, Leandra, feminista de 32 años, señala que resulta complicado tener amigos hombres, pues pensar en lo sexual y separarlo de lo afectivo es difícil. Los amigos varones: o fueron parejas o son compañeros sexuales o podrían llegar a serlo en algún momento. Sin embargo, Leandra siente que eso impide una apertura a la intimidad. Eso se debe, según ella, a que casi nunca es fácil el ejercicio de abrirse a la amistad plena con los hombres. Tan difícil como lo es abrirse a la intimidad erótica con las mujeres: ahí se ve el problema de establecer vínculos distintos, escalonados. A su juicio, el problema del género también incide en apostar por relaciones de pareja, ya que fomenta la dependencia de la mujer con respecto al varón. 
Ernestina, lideresa campesina, no considera obstáculos en su proceso: ella asegura ser capaz de superarlos sin problemas. Pone de ejemplo lo que le sucedió cuando uno de sus compañeros, el papá de uno de sus hijos, le criticaba su trabajo comunitario, por lo cual su relación duró muy pocos meses; en cambio con su actual compañero han podido reconocerse más, porque hay afinidades en el tema. Para que pueda haber una relación adecuada, se requiere del apoyo y la comprensión de la pareja; por ejemplo, para distribuir tareas de cuidado de los hijos y apoyo doméstico. Sin embargo, sabe de compañeras en situaciones similares que enfrentaban dificultades con sus compañeros sentimentales, pero ella no ve que sean cruciales en la vida cotidiana.

La vida de una lideresa, en términos de Ernestina, es distinta de las vidas de otras mujeres: una lideresa debe estar disponible todo el tiempo para participar en los procesos de base, que no tienen horario; sin embargo, no siente que le afecte esa distinción entre liderazgo y vida privada. Es interesante notar cómo la distinción entre lo público y lo privado es un tema que pertenece a los conglomerados urbanos, a la proximidad más íntima; pues en las zonas rurales esa diferenciación es menos notoria, al menos en su experiencia personal.

Para Fabiola, lideresa barrial, la situación es similar. Se es líder las 24 horas: no solo en los espacios donde se hacen programas o proyectos específicos, sino en la cotidianidad. Es un trabajo social que implica recibir personas a las nueve de la noche u organizar su casa para atender adultos en aprendizaje de lectoescritura. Son actos de mediación: " $a$ la gente le puede dar miedo [tratar con personas de otros sectores del barrio] pero uno tiene que manejar la situación. Uno tiene que buscar estrategias para que los estudiantes [del proceso en el que ella participa] se sientan bien". Algo parecido ocurre con el estigma que tiene el barrio frente a la ciudad. Explica: "aqui hablamos mucho de la estigmatización que nos tienen afuera, pero aqui mismo nos estigmatizamos entre nosotros mismos". Sin embargo, sus habilidades se han fortalecido desde que empezó a recibir capacitaciones y apoyo de organizaciones que intervenían en el sector.

Fabiola reconoce el impacto del liderazgo en la vida privada y en la vida de familia. Este liderazgo ha mejorado la percepción sobre sí misma como mujer y también su relación de pareja. Su condición le ha permitido superar los conflictos derivados del maltrato de pareja y establecer límites que ya no se volverán a cruzar. Por otro parte, Fabiola juzga problemático el exceso de líderes en un espacio limitado. Por ejemplo, en su sector hay muchos líderes que de manera dispersa intervienen en la construcción de procesos paralelos. Eso disminuye la motivación, porque resulta muy difícil direccionar las acciones de forma eficaz para cambiar la cara al barrio y que sea percibido diferente en la ciudad. Para ella los temas que cada líder aborda dependen del género. Mientras que los hombres se focalizan en los criterios y las necesidades de los hombres, las mujeres líderes tratan de llegar a toda la población. Afirma que las mujeres que lideran procesos se vuelven más fuertes, más rudas: sea para alzar la voz, para que no crean 
que es la silenciosa, para participar. Finalmente, hombres y mujeres logran articularse, pues se anudan debido a las metas compartidas.

Una de las tensiones que Fernanda confiesa vivir se debe a la educación cristiana, no católica, que recibió desde niña. Aprendió la necesidad de darse importancia a sí misma, al tiempo que veía necesario respetar la diversidad de los otros. De modo que la tolerancia, tan invocada en espacios sobre el deber ser (reivindicaciones sociales, educación, etc.), termina por convertirse en un punto de tensión. Fernanda lo explica de la siguiente manera:

Yo era de las que decía que la tolerancia es lo peor que puede hacer uno, porque para míla tolerancia era también aguantarse lo malo, porque lo malo para mí no es lo malo para todo el mundo, y que lo bueno para míno es lo bueno para todo el mundo. Eso me implicó un cambio de pensamiento dentro del movimiento estudiantil. [Fernanda, lideresa estudiantil, 23 años]

Y evidentemente, dentro de estas tensiones también se localiza la desigualdad en términos de la representación dada a las mujeres: Fernanda advierte que hay una inequidad sistemática en la representación estudiantil dada a las mujeres, que ella ve reflejada así:

Asumirme como una mujer líder allí, es algo que uno se va dando cuenta con la práctica. Por lo general las mujeres no son las que más sobresalen en ese proceso, pues en lo estudiantil vamos a encontrar muchos compañeros que casi siempre son los que echan el discurso, son los que hablan duro; pero las mujeres no tanto, somos más bien pocas. Aunque en las organizaciones de base las mujeres son las que sacan adelante la cuestión, por lo general, las compañeras son las que van a conseguir las cosas, hacen los carteles, están $100 \%$ dedicadas, pero no tienen una participación en lo público, su trabajo no es destacado.

La dinámica masculina en la que se mueve le exige más. Los compañeros varones por defecto son los que asumen las tareas de liderazgo; para las mujeres, entonces, hay más tareas y expectativas por cumplir. Si una mujer sobresale y se destaca le "echan los perros"; eso es algo que toca aprender a lidiar. En casi todos los espacios la mujer que logra convocar y movilizar, se destaca ante los demás y se hace punto de referencia; además gana atractivo y la buscan, la invitan a salir, se vuelve un objeto de deseo. Para Fernanda eso implica estar siempre muy alerta, sin chocar, pero hablando serio, con el cuerpo y con los gestos. 


\section{Reflexiones finales}

Después de este recorrido por la vida de estas mujeres, se pueden extraer muchos elementos para pensar la relación entre lo público y lo privado.

La vida personal de las protagonistas de estos relatos, en sus entornos, está íntimamente ligada con la participación en sus comunidades. Está atravesada por la presencia de más personas y también por vínculos, por sentimientos de responsabilidad hacia otros y por pasiones distintas a las esperadas en los hombres. Por ello, en sus vidas no es posible reconocer una diferenciación clara entre lo privado y lo público que concuerde con la asignación típica de valores que caracterizan la dicotomía de lo masculino y femenino. De modo que lo propio y lo ajeno no pasa por la idea de propiedad sino por la de necesidad: quien necesita algo de ellas, lo pide o da a entender que lo requiere. La idea de dar al otro (criticable, en unos casos; naturalizada, en otros) es parte de su sentimiento comunitario. Y dado que los elementos que les pertenecen no son solamente objetos materiales sino sobre todo saberes, vivencias, experiencias, ideas, se comparten sin egoísmos.

En compartir el tiempo, el conocimiento, las tácticas de vida, hasta el cuerpo, empleado a veces como instrumento de transgresión simbólica, hay una apropiación de la idea de comunidad que va más allá de satisfacer las necesidades propias, idea en la que los otros tienen un lugar muy especial, pues sin ellos no se puede vivir. A su vez, las redes y los vínculos filiales merecen un lugar especial de reconocimiento, pues suplen las ausencias de las instituciones (trabajo, salud, apoyo social), cuando estas operan desde un esquema patriarcal (burocratizado, indolente, parsimonioso).

Como se ha podido ver, los modelos de vida que cada una de las lideresas presenta son variados; por lo que establecer patrones de similitudes que hablen de la forma en que estas mujeres llevan su vida entre lo público y lo privado es, por lo menos, complicado. Sin embargo, sí es posible trazar algunos parámetros que corroboren la existencia de una línea -si acaso existe- demasiado tenue que valore el rol de ellas en la sociedad como público o privado.

A lo largo de la investigación se ha estudiado el día a día de mujeres que por una u otra razón han transgredido el rol al que históricamente deberían responder. El mismo hecho de que sean catalogadas como lideresas, pone en jaque la distribución de poderes en la cual siempre ha sido privilegiado el hombre. El papel de líder, de mando, de poder, siempre ha correspondido a lo masculino. Que una mujer asuma este papel obliga a pensar si las caracterizaciones históricas de lo femenino son correctas e inamovibles, o si por el contrario es necesario replantearlas.

Lo que nos muestra la investigación es que efectivamente las cargas valorativas que se les ha dado a los dos espectros de la dicotomía son contingentes, y no necesariamente representan algo positivo frente a algo negativo. En estos casos, lo público pocas veces tenía que ver con lo productivo o con la fuerza, que son valores que normalmente aso- 
ciados con lo masculino; los valores de lo masculino y lo femenino se entremezclan de la forma en que estas mujeres consideren más conveniente para hacer su trabajo. Como muchas lo afirman, su rol de lideresas las obliga a llevar una vida netamente pública, al servicio de la comunidad; y lo hacen de la mano del desarrollo de labores de cuidado, como la alimentación y la educación. Está también el caso de aquellas que siendo mujeres deciden asumir como suyos los valores masculinos, de manera que se les pueda tomar en serio en la labor que realizan; pero que en su intimidad requieren de algún escape que les permita reconocerse como femeninas. Es el caso de las lideresas que militan como activistas, que necesitan mostrar un carácter fuerte para que su labor valga, para que sus pares masculinos no ejerzan presión sexual sobre ellas; y cuyos valores femeninos son relegados a unos pocos que hacen parte de su intimidad.

La existencia de mujeres, que no solo se limita a los casos aislados de las lideresas entrevistadas, que articulan su vida en ambos espectros de lo femenino y lo masculino, y que de manera indistinta se valen de los valores que caracterizan cada cara de la dicotomía para desarrollar sus roles, permite ver lo problemático de priorizar la asignación forzosa de roles en razón de criterios históricos altamente debatibles.

Este estudio invita a repensar la forma en que se concibe el trabajo de la mujer, la valoración que se le da y, por ende, el rol subsidiario que se le ha asignado. Como se ha visto, estas lideresas comunitarias, sin pensar demasiado en las categorías en que se encuadra su rol, mezclan lo femenino y lo masculino para impactar en sus vidas y en la comunidad en la que se desenvuelven.

\section{Referencias}

ARIAS, V. GONZÁLEZ, L. F. Y FERNÁNDEZ, N. (2009) "Constitución de sujeto político: historias de vida política de mujeres afrodescendientes", en: Universitas Psychologica. 8(3), 639-652.

BERTAUX, D. (1993). "De la perspectiva de la historia de vida a la transformación de la práctica sociológica", en: Marinas, J. y Santamarina, C. La historia oral. Métodos y experiencias. Madrid: Ed. Debate.

DE CERTEAU, M. (2000). La invención de lo cotidiano 1. Artes de hacer. México D.F.: Ed. Universidad Iberoamericana.

HOLMES, M. (2007). Gender and Everyday Life. NY: Routledge.

LAZZARATO, M. Y NEGRI, A. (2012). “Trabajo inmaterial y subjetividad”. En: Trabajo inmaterial. Formas de vida y producción de subjetividad. Recuperado en: http://www.rebelion.org/ docs/121986.pdf Visitado en mayo de 2012. 
MARTUCELLI, D. (2007). Cambio de rumbo: La Sociedad a Escala del Individuo. Santiago de Chile: LOM Eds.

WISCHERMANN, U. (2004). "Feminist Theories on the Separation of the Public and Private: Looking back, Looking forward”, en:Wischermann, U. y Mueller, K. Women in German Yearbook, vol. 20, pp. 184-187. 